\title{
Pobres no Ter, Ricos no Ser: Trabalho Voluntário e Motivação na Pastoral da Criança
}

\author{
Virgínia Donizete de Carvalho \\ Washington José de Souza
}

\section{Resumo}

É objetivo deste estudo descrever os componentes da motivação no trabalho voluntário de lideres comunitários da Pastoral da Criança atuantes em Natal, RN, tomando como referência a Teoria da Expectância de Vroom (1964). Foi realizado, inicialmente, um mapeamento do perfil sociodemográfico dos voluntários e, a partir das informações obtidas, selecionaram-se nove respondentes para entrevistas concernentes aos conteúdos de valências, expectativas e instrumentalidades atribuídas aos resultados do trabalho. A força motivacional pode ser considerada mediana, porque, embora as valências e expectativas identificadas tenham sido expressivas, a instrumentalidade foi baixa em alguns aspectos. Importa registrar o desafio epistemológico enfrentado, por se tratar de estudo do comportamento humano em uma organização voluntária, tendo como referência literatura fundamentada na compreensão do trabalho com fins econômicos, o que exigiu a transposição dos conceitos para uma realidade em que o trabalho apresenta outra conotação. Por fim, sendo o Modelo da Expectância uma teoria de processo, os resultados indicados retratam uma configuração momentânea, o que exige acompanhamento contínuo com vistas a incorporar possíveis (re)arranjos circunstanciais.

Palavras-chave: trabalho; organizações voluntárias; motivação.

\begin{abstract}
The general purpose of this study was to describe, through the Vroom's (1964) Expectancy Theory, the motivational components of voluntary work developed by Pastoral da Criança volunteers in Natal, Brazil. Based on the model mentioned, an interview draft was applied to a group of 9 volunteers. Previously, all leaders in Natal response a questionary regarding their social-demographic profile. The analysis of the results indicated that the volunteers' motivational force can be considered medium, because although the described valences and identified expectations have been, in a general, high, the verified instrumentality was less expressive. It is important to state the epistemological challenge regarding this research because studies of human behavior in voluntary organizations are scarce. In the other hand, there is a large literature take into account work as a synonym of employ and income. Finally, it is important to point out that, considering the Expectancy Model as a motivational process theory, the results must be taken as effects of a specified moment and context.
\end{abstract}

Key words: work; voluntary organizations; motivation. 


\section{INTRODUÇÃO}

A atividade laboral humana em organizações tem merecido a atenção de estudiosos na tentativa de compreender os fatores que influenciam o desempenho das pessoas em situação de trabalho. No tocante aos estudos motivacionais, várias teorias foram propostas ao longo das últimas décadas, dentre as quais a Teoria da Expectância, de Vroom (1964), que declara que a motivação se encontra relacionada aos resultados que uma pessoa busca e sua estimativa de que a ação conduzirá aos resultados desejados.

Tal modelo tem sido aplicado por diversos estudiosos no mundo, o que, no Brasil, vem ocorrendo há mais de duas décadas, conforme ilustram os estudos de Ferris, Dillard e Nethercott (1980), Saks, Wiesner e Summers (1994), Allen et al. (1997), Sanchez, Truxillo e Bauer (2000), Borges e Alves Filho (2001), Alves Filho e Araújo (2001), Régis e Calado (2001) e Erez e Isen (2002).

Não obstante o elevado número de pesquisas que têm como tema a motivação, no geral a ênfase dos estudos recai em situação de trabalho em organizações de mercado, embora o crescimento do terceiro setor na economia represente uma demanda de compreensão do comportamento organizacional, especialmente quando se considera o tipo de racionalidade que orienta as iniciativas solidárias.

Estas constatações nortearam a realização da presente investigação, destinada a compreender o comportamento e a motivação na atividade voluntária, com base no modelo proposto por Vroom (1964). Nesse desígnio, a organização selecionada foi a Pastoral da Criança, tendo em vista a abrangência do trabalho realizado no Brasil e o reconhecimento do mérito em nível internacional.

Os números do Quadro 1, por si, indicam a importância social da organização no Brasil, no Estado do Rio Grande do Norte e, em particular, no município de Natal.

\section{Quadro 1: Números e Níveis de Atuação da Pastoral da Criança}

\begin{tabular}{l|c|c|c}
\hline \multicolumn{1}{c|}{ Dimensão } & Brasil & Rio Grande do Norte & Natal \\
\hline Voluntários & 200.000 & 1953 & 359 \\
\hline Famílias & 1.200 .000 & 18.921 & 1.659 \\
\hline Crianças atendidas & 1.566 .237 & 25.686 & 2.115 \\
\hline Comunidades & 32.473 & 544 & 58 \\
\hline Municípios & 3.549 & 99 & - \\
\hline
\end{tabular}

Fonte: adaptado de Coordenação da Pastoral da Criança (2003). 
A abrangência geográfica, a relevância social das atividades e a repercussão internacional do trabalho desenvolvido pela Pastoral da Criança são, assim, indicadores da pertinência da presente investigação, cujos desafios e contribuições epistemológicos residem em três pontos:

- discutir a motivação no trabalho voluntário a partir de um referencial teórico que, não raro, enfatiza elementos de racionalidade instrumental, tomando o trabalho sob a ótica de mercado;

- alcançar a Força Motivacional, apropriando a proposição original de Vroom, de natureza quantitativa via equação matemática, mediante o emprego de procedimentos qualitativos;

- fornecer novos elementos ao quadro conceitual dos estudos do comportamento organizacional, tomando como base o trabalho solidário de caráter voluntário.

Uma vez que a pesquisa abordou o tema motivação em uma organização de trabalho voluntário, a contextualização das organizações solidárias e a caracterização da instituição estudada são os assuntos tratados a seguir. Após a revisão bibliográfica acerca da motivação no trabalho, com foco na Teoria da Expectância, são expostos os procedimentos metodológicos utilizados, os resultados da investigação e, por fim, as considerações finais e indicações para estudos futuros do tema.

\section{Contextualização do Estudo: Discutindo a Diversidade do Setor SOCIAL}

O papel do terceiro setor na sociedade contemporânea é tema de discordância no meio acadêmico. Para uma corrente, trata-se de estratégia ideológica que serve aos interesses neoliberais. Sob essa perspectiva crítico-reflexiva, Paula (1997), Vainer (2000), Petras (1998) e Montaño (2002), dentre outros, consideram que a manutenção do papel regulador do Estado na esfera econômica, aliada à desregulamentação e à redução de investimentos sociais, favorece a proliferação de organizações sociais que beneficiam a acumulação de capital. Outra corrente advoga a idéia de que há um caráter positivo na proliferação de tais organizações em virtude do crescimento da autonomia dos indivíduos na condução dos problemas socioeconômicos, inerentes às macrotendências contemporâneas. Dentre os defensores do terceiro setor, aqui denominados de corrente positivoprogressista, Andion (2001), Serva (1997), Fischer e Melo (2003), Fernandes (1994) e Singer (2000) imprimem a essa mudança a oportunidade de autoorganização da sociedade civil. 
Independentemente da controvérsia que alimenta a discussão acerca das verdadeiras razões para a atual expansão desse campo da economia, é fato que as organizações sociais se expandem rapidamente e, assim, está posto aos construtores do conhecimento organizacional o desafio de mapear os contornos desse fenômeno. Tal afirmação torna-se mais pertinente, quando se considera a escassez de critérios de definição, a amplitude relativa à forma de constituição político-jurídica e a vasta nomenclatura: terceiro setor, economia solidária, economia social, organizações não governamentais, organizações sem fins lucrativos, organizações voluntárias, organizações sociais, entre outras.

Nesse sentido, um exercício acadêmico importante foi desenvolvido por Andion (2001). Inspirada na noção de economia substantiva, definida por Polanyi (1975), e nos conceitos de mundo do sistema e de mundo da vida, estabelecidos por Habermas (1989), a autora ordenou uma classificação que põe as organizações do campo social em três grupos (Quadro 2), tomando como eixo o princípio de regulação e o modo de ação particular, segundo o objetivo organizacional.

\section{Quadro 2: Classificação das Organizações que Atuam no Campo Social}

\begin{tabular}{ll}
\hline \multicolumn{1}{c}{ Grupo } & \multicolumn{1}{c}{ Características } \\
\hline Economia social & $\begin{array}{l}\text { Têm como função a produção de bens e serviços, visando responder às necessidades de } \\
\text { seus membros, tais como as cooperativas e as mutuais de crédito. A forma de regulação é } \\
\text { baseada na troca mercantil, aproximando-se mais da esfera do Mercado. Elas têm fins } \\
\text { econômicos, mas a sobra é redistribuída entre os membros proporcionalmente. }\end{array}$ \\
Terceiro setor & $\begin{array}{l}\text { O princípio de regulação seria a redistribuição de recursos, públicos ou privados, visando } \\
\text { ao bem comum, o que aproxima seu papel ao do Estado, quando busca a diminuição das } \\
\text { desigualdades sociais. Neste grupo estão as instituições, as fundações empresariais e } \\
\text { públicas, as ONGs internacionais e as intermediárias entre financiadores e comunidade. }\end{array}$ \\
$\begin{array}{l}\text { Economia } \\
\text { solidária }\end{array}$ & $\begin{array}{l}\text { Organizações filantrópicas criadas a partir da mobilização da sociedade civil e que não } \\
\text { possuem fins lucrativos. A economia solidária compreende as associações civis de } \\
\text { caráter público, as organizações comunitárias, as organizações voluntárias e as ONGs de } \\
\text { atuação social direta. Neste grupo prevalecem formas de regulação baseadas na } \\
\text { reciprocidade, tais como o dom e o voluntariado que, por sua vez, são indissociáveis das } \\
\text { relações pessoais presentes na esfera comunitária. }\end{array}$ \\
\hline
\end{tabular}

Fonte: Andion (2001).

A partir desse esboço, as organizações definidas como pertencentes à Economia Social e ao Terceiro Setor aparecem sob maior interface com o Estado ou com o mercado; por isso, a forma de funcionamento se aproxima da lógica econômica, ou do mundo do sistema. De outra forma, as organizações designadas como de Economia Solidária têm maior imbricação com a esfera da sociedade civil, prevalecendo, nestes casos, as relações de proximidade e reciprocidade - 0 mundo da vida. Nesta investigação, foi adotada tal classificação para enquadrar a Pastoral da Criança no conjunto das organizações de Economia Solidária, voltada ao trabalho voluntário. 
No Brasil, o trabalho voluntário é regulamentado pela Lei 9.608, sancionada pelo então presidente Fernando Henrique Cardoso, em fevereiro de 1998. De acordo com essa Lei, independentemente do motivo que leva uma pessoa ao serviço, para ser caracterizado como voluntário, o trabalho deve ocorrer por vontade própria, sem remuneração, prestado por um indivíduo isoladamente e para uma organização sem fins lucrativos, com objetivos públicos.

Na condição de organização que congrega o maior número de voluntários em nível nacional, a Pastoral da Criança surgiu da compreensão cientifica de que a maior parte das doenças e mortes infantis, nos países do terceiro mundo, poderia ser facilmente evitada através de tecnologias simples e baratas.

No ano de 1983, a Conferência Nacional dos Bispos do Brasil (CNBB) confiou a tarefa de criação e desenvolvimento da Pastoral da Criança à médica pediatra e sanitarista Zilda Arns Neumann e a Dom Geraldo Majella Agnelo, então arcebispo de Londrina. Uma primeira experiência foi iniciada no município de Florestópolis, que apresentava o maior índice de mortalidade infantil no Estado do Paraná.

Não obstante o fato de ser uma organização originalmente articulada no âmbito da Igreja Católica, a Pastoral é um organismo autônomo. A estrutura é composta por uma hierarquia de coordenações, que começa na Coordenação Comunitária, passando pelas Coordenações Paroquiais, Diocesanas, Estaduais e a Coordenação Nacional. A Coordenação Comunitária é, portanto, a menor unidade administrativa, constituída por uma equipe de líderes comunitários responsáveis pela implementação das ações.

Os líderes comunitários participam de cursos de capacitação e acompanham o desenvolvimento e a educação de crianças. Entre as principais tarefas estão: visitas domiciliares mensais às famílias acompanhadas, realização do dia da vigilância nutricional, promoção de reuniões e encontros com as famílias, estabelecimento da articulação com o sistema de saúde e com outras pastorais e movimentos da comunidade e registro das informações relativas ao desenvolvimento das crianças e das gestantes no Caderno do Líder.

O objetivo principal da Pastoral é atuar na promoção humana, via combate à mortalidade infantil, à desnutrição, à violência doméstica e à marginalidade social. Visando à oferta de suporte às famílias e comunidades, a Pastoral desenvolve, também, outros projetos complementares às ações básicas, tais como: alfabetização de jovens e adultos, programa de geração de renda, programa de segurança alimentar, planejamento familiar natural, assistência à terceira idade e comunicação social.

Durante os 20 anos decorridos desde a criação, a Pastoral da Criança é apontada 
como uma das mais importantes organizações do mundo a trabalhar nos campos da saúde, nutrição e educação da criança, do ventre materno aos seis anos de vida. Um número superior a 30 prêmios marca a trajetória da organização, merecendo destaque o Prêmio UNESCO na categoria de Direitos Humanos e Cultura de Paz em 2000; a primeira colocação entre equipes de voluntários do Brasil, pela Fundação Kanitz em 1999/2000 e as indicações do governo brasileiro ao Prêmio Nobel da Paz nos anos de 2001, 2002 e 2003. Em 2004, a Dra. Zilda Arns foi escolhida, na opinião de jornalistas e leitores do jornal "o Globo", a personalidade do ano, recebendo o prêmio Faz Diferença que homenageou pessoas que se destacaram durante o ano de 2003 por suas iniciativas, vitórias e exemplos, ajudando a mudar o Brasil.

\section{Trabalho e Motivação: uma leitura}

Tradicionalmente, de acordo com Quijano e Cid (2000), a classificação das diferentes abordagens da motivação ocorre em duas categorias: teorias motivacionais de conteúdo e de processo.

As teorias motivacionais de conteúdo prendem-se à descrição do conteúdo das motivações e observam o que energiza o comportamento humano. Essas teorias englobam as variáveis individuais ou situacionais que se supõe sejam responsáveis pela conduta, isto é, têm o foco em fatores que provocam e estimulam a busca de estratégias que satisfazem certas necessidades à procura do estado de equilíbrio (Quijano \& Cid, 2000). Dentre as propostas teoricas desta categoria destacamse a Hierarquia das Necessidades de Maslow, a Teoria dos Dois Fatores de Herzberg, a ERC (existência, relacionamento e crescimento) de Alderfer e a Teoria das Necessidades de McClelland.

As teorias motivacionais de processo têm como objetivo precípuo explicar o processo através do qual a conduta tem início, se mantém e termina (Bowditch \& Buono, 1992). Enquadram-se nesta categoria a Teoria da Eqüidade de Adams, a Teoria da Avaliação Cognitiva de Deci, a Teoria do Estabelecimento de Objetivos de Locke e a Teoria da Expectância de Vroom.

Adotada como suporte teórico-metodológico desta investigação, a Teoria da Expectância de Vroom (1964) busca predizer escolhas entre empregos, tarefas e níveis de esforço que produzem os mais altos benefícios percebidos. É uma teoria cognitivista que assume existir uma relação entre o esforço realizado e a execução ou rendimento no trabalho. O cerne é, portanto, o processo de motivar e não exatamente o conteúdo. 
Na visão de Vroom (1964), o processo motivacional se encontra fundamentado pelas relações existentes entre três variáveis: valência, expectativa e instrumentalidade.

Na condição de força da preferência de uma pessoa por determinado resultado, a valência expressa o montante do desejo de se atingir um objetivo pessoal, podendo possuir valores tanto positivos como negativos, à medida que as pessoas possuem preferências positivas ou negativas por determinado resultado. Desse modo, o foco é a relação recompensas-metas pessoais, isto é, o grau em que as recompensas vêm satisfazer os objetivos individuais e a atratividade destas potenciais recompensas para o indivíduo (Régis \& Calado, 2001).

A expectativa é expressa em termos da probabilidade. Trata-se da estimativa do individuo ao julgar até que ponto o desempenho será determinado pelo esforço despendido. Por expressar a probabilidade de uma conexão entre esforço e desempenho, a expectativa pode ser descrita segundo a intensidade. Se o indivíduo não acreditar que um dado esforço possa levar a um desempenho desejado, a expectativa é baixa. Por outro lado, se ele tem confiança de que o esforço possa levar à conclusão da tarefa, a expectativa é elevada. Segundo Levy- Leboyer (1994), o componente da expectativa é aquilo que cada um acredita ser capaz de fazer, aquilo que espera como resultado provável dos seus esforços.

A instrumentalidade, por sua vez, consiste no grau de relação percebido entre o desempenho e a obtenção dos resultados. A relação desempenho-recompensa, portanto, constitui-se no foco da instrumentalidade. Se um trabalhador percebe que as recompensas estão relacionadas ao seu desempenho, a instrumentalidade tenderá a ser avaliada positivamente. Todavia, não havendo clareza nesta relação, uma baixa estimativa poderá ser feita (Quijano \& Cid, 1998).

As variáveis acima explicitadas relacionam-se sob um modelo multiplicativo, resultando na força motivacional, que consiste na quantidade de esforço ou pressão de uma pessoa para motivar-se (Vroom, 1964). São apresentadas, pois, na seguinte equação matemática:

$\mathrm{FM}=\mathrm{E}$ [6 Vi Ii], onde:

$\mathrm{FM}=$ Forca Motivacional

$\mathrm{E}=$ Expectativa

$\mathrm{V}=$ Valência

I = Instrumentalidade 
Vale ressaltar que, por se tratar de um modelo multiplicativo, a existência de uma variável com valores predominantemente negativos ou baixos instrumentalidade, por exemplo - poderá ocasionar uma força motivacional negativa ou baixa. Isto ocorre, mesmo que uma das variáveis - valência, por exemplo - apresente valor elevado. Em outras palavras, se um indivíduo deseja e valoriza determinada recompensa e tem expectativas elevadas de que seu esforço irá resultar no nível de desempenho necessário à obtenção da mesma, mas, por outro lado, não recebe as recompensas proporcionais ao seu desempenho, ele tenderá a se desmotivar para a realização da tarefa. Da mesma forma, se ele tem expectativas de alcançar um bom desempenho e percebe que este é devidamente recompensado, mas não valoriza ou não deseja tal recompensa, a motivação para a execução da atividade será reduzida ou baixa.

Assim, o resultado da força motivacional prediz quão motivado está um individuo. De acordo com Muchinsky (1994, como citado em Alves Filho \& Araújo, 2001), a Teoria da Expectância proporciona uma base racional rica para a compreensão da motivação em determinado trabalho, pois cada um de seus componentes constitui um marco para analisar o processo de motivação.

Cabe, aqui, tecer uma crítica ao enfoque que as teorias motivacionais, de modo geral, têm recebido nos estudos em Administração. Não raro, os estudiosos da Administração tomam o trabalho como meio de sobrevivência, estreitamente relacionado aos sistemas de vantagens e remuneração, ou seja, voltado a fins econômicos. Desse modo, são negligenciadas outras formas de atividade laboral que podem gerar desempenho vitorioso, ou sucesso profissional ou, ainda, meio para auferir recompensas que transcendem a relação puramente material, como é o caso do trabalho voluntário.

Nesse sentido, é oportuna uma alusão à discussão marxista concernente ao duplo caráter do trabalho e da mercadoria, segunda a qual, conforme Souza (1999), o valor-de-uso do trabalho tem sido reduzido ao valor-de-troca e mantido somente como condição necessária para a integralização do processo de valorização do capital. Esse padrão, legitimado em uma sociedade centrada no mercado, manifesta-se impregnando a compreensão acerca do comportamento humano nas organizações em que o trabalho tende a ser abordado a partir da atividade laboral que cria valor-de-troca, reduzindo o trabalho humano a mercadoria. Por esta razão, a apreciação da temática comportamental na atividade voluntária vai de encontro a uma série de discussões empreendidas no campo da gestão de pessoas por diferir, em essência, da restrita concepção acerca da natureza do trabalho humano, reduzida à idéia de emprego e/ou de atividade geradora de renda. 


\section{Construção da Pesquisa}

Os pontos centrais da presente investigação, que pode ser classificada como qualitativa e descritiva (Gil, 1994), foi definir a valência, identificar as expectativas dos voluntários em relação aos resultados do trabalho e verificar se o desempenho é percebido como instrumental para a obtenção destes resultados. A partir desses elementos, foi desenvolvido um exercicio subjetivo, para inferir a respeito da força motivacional resultante.

O público-alvo foi constituído por 178 líderes comunitários atuantes nas 15 paróquias em que a Pastoral da Criança exerce atividades no município de Natal. $\mathrm{O}$ procedimento inicial foi aplicar um questionário estruturado, adaptado do modelo do IBGE no censo demográfico brasileiro, junto a toda a população, para identificar o perfil sociodemográfico dos respondentes. As informações coletadas nessa fase receberam tratamento estatístico de frequiência e cruzamento de variáveis através de rotinas disponíveis no Statistical Package for Social Sciences (SPSS). O intuito, nessa fase, foi mapear a composição do perfil dos voluntários, visando à seleção de atores para uma fase posterior de entrevista.

Conforme discussão adiante, o perfil predominante dos atores que atuam na Pastoral da Criança em Natal é facilmente identificável. Entretanto, a seleção dos atores para a fase de entrevista contemplou a diversidade do grupo, em virtude de se trabalhar com a possibilidade de manifestações motivacionais diversas, segundo o perfil sociodemográfico do informante, o que não foi confirmado. Esse procedimento seguiu, por um lado, a recomendação de Bardin (1977), quando afirma que a análise em profundidade pode se efetuar junto a uma pequena parcela da população, desde que esta seja uma expressão do universo inicial.

Por outro lado, foi observado um procedimento descrito por Manson (1996), e anteriormente aplicado por Souza (1999), segundo o qual, na definição de uma amostra intencional, não importa saber se há representatividade estatística da população, uma vez que, por motivos práticos, esta é geralmente reduzida. A sistemática de definição dos informantes pode, então, seguir um critério dinâmico e cessar no instante em que o pesquisador percebe ter alcançado um ponto teórico de saturação, a theory-saturation point, ou seja, que as informações coletadas não diferem em essência e, portanto, são suficientes para traçar um quadro do que está acontecendo.

Assim, foram selecionados para a fase de entrevistas nove voluntários, de ambos os sexos, tendo sido contemplada, ainda, a diversidade encontrada em termos de 
estado civil, escolaridade, tempo de atuação na Pastoral, nivel de renda da familia e situação de atividade remunerada, empregado ou não. O perfil dos atores selecionados para a fase de entrevistas encontra-se no Quadro 3.

\section{Quadro 3: Perfil dos Voluntários da Pastoral da Criança Entrevistados}

\begin{tabular}{|c|c|c|c|c|c|c|c|c|c|}
\hline Perfil & L1 & $\mathbf{L 2}$ & L3 & L4 & L5 & L6 & L7 & L8 & L9 \\
\hline Idade & 39 & 35 & 43 & 25 & 39 & 23 & 42 & 19 & 57 \\
\hline $\operatorname{Sexo}^{1}$ & $\mathrm{~F}$ & $\mathrm{~F}$ & $\mathrm{~F}$ & M & $\mathrm{F}$ & M & $\mathrm{F}$ & $\mathrm{F}$ & $\mathrm{F}$ \\
\hline Estado Civil $^{2}$ & $\mathrm{D}$ & $\mathrm{C}$ & $\mathrm{C}$ & S & $\mathrm{D}$ & $\mathrm{C}$ & S & S & S \\
\hline Escolaridade $^{3}$ & EFI & EMC & EMC & EMC & EMC & EMC & EMC & EMC & ESC \\
\hline Tempo de atuação & $2 \mathrm{a}$. & $10 \mathrm{a}$ & $11 \mathrm{a}$. & $5 \mathrm{a}$. & $1 \mathrm{a}$. & $3 \mathrm{a}$. & $3 \mathrm{a}$. & $10 \mathrm{~m}$. & $13 \mathrm{~m}$. \\
\hline Atividade remunerada & Não & Não & Sim & Sim & Sim & $\operatorname{sim}$ & Não & não & Sim \\
\hline Nível de Renda ${ }^{4}$ & Até 1 & 3 a 4 & 1 a 2 & 3 a 4 & 1 a 2 & 3 a 4 & Até 1 & 3 a 4 & 1 a 2 \\
\hline
\end{tabular}

Fonte: Dados da pesquisa (2003).

Legenda: 1 -F: feminino; M: masculino/ 2 - S: solteiro; C: casado; D: divorciado/ 3 - EFI: ensino fundamental incompleto; EMC: ensino médio completo; ESC: ensino superior completo/ 4 - salários mínimos.

As entrevistas semi-estruturadas, gravadas com o consentimento dos atores, foram desenvolvidas com base no roteiro sintetizado no Quadro 4. Em essência, as questões foram destinadas ao alcance das dimensões da Teoria de Expectância: valências, expectativas e instrumentalidades atribuídas pelos voluntários.

\section{Quadro 4: Síntese do Roteiro de Entrevista}

\begin{tabular}{|l|}
\hline 1. Como você chegou à Pastoral da Criança \\
\hline 2. O que você faz na Pastoral da Criança? \\
\hline 3. Por que você trabalha na Pastoral da Criança \\
\hline 4. Que benefícios você busca com o seu trabalho? \\
\hline 5. Qual é a importância desse trabalho para você? \\
\hline 6. O trabalho que você faz contribui para o alcance dos seus objetivos? \\
\hline 7. Existem outras coisas que vocês deveriam fazer para alcançar os resultados esperados? \\
\hline 8. Como você se define antes e depois da Pastoral da Criança? \\
\hline
\end{tabular}


No tratamento das informações coletadas foi utilizado o procedimento metodológico proposto por Bardin (1977, p. 21), em uma das técnicas da análise de conteúdo, denominada análise categorial. De acordo com a autora,

a análise de conteúdo se presta ao estudo das motivações, atitudes, valores, crenças e tendências, sendo definida como um conjunto de técnicas de análise das comunicações, visando, por procedimentos sistemáticos e objetivos de descrição do conteúdo das mensagens, a obter indicadores quantitativos, ou não, que permitam a inferência de conhecimentos relativos às condições de produção/recepção (variáveis inferidas) das mensagens.

As categorias de análise, discutidas adiante, e os respectivos indicadores surgiram das falas dos sujeitos, tendo sido utilizados, como eixo norteadores, os estudos de Borges e Alves Filho (2001) e de Régis e Calado (2001), que realizaram pesquisas, aplicando o referido modelo. Além desses, foi igualmente útil um trabalho desenvolvido por Morin, Tonelli, e Pliopas (2003) que, embora não trate diretamente do tema motivação, aborda um campo correlato: o sentido do trabalho nas organizações.

O estudo desenvolvido por Borges e Alves Filho (2001) consistiu na elaboração e avaliação das qualidades psicométricas de um questionário destinado a mensurar componentes do significado do trabalho e da motivação no trabalho, junto a profissionais de saúde e bancários. A partir deste estudo, foram identificados fatores relacionados a cada uma das dimensões do Modelo da Expectância.

Régis e Calado (2001), por sua vez, analisaram o quadro motivacional dos docentes do Centro Federal de Educação Tecnológica da Paraíba (CEFET-PB) para o envolvimento em um Programa de Qualidade. Para tal foi utilizado um questionário, anteriormente aplicado em estudo de caso americano, além de indicadores relativos às dimensões do modelo de Vroom (1964), validados em painéis realizados com os professores, tendo sido listadas 27 recompensas percebidas com relação ao engajamento no Programa.

O estudo de Morin, Tonelli, e Pliopas (2003) reuniu, a partir da exploração qualitativa de informações obtidas em entrevistas, elementos destinados à construção de um instrumento de coleta válido para pesquisas no tema sentidos do trabalho para brasileiros.

Os fatores motivacionais identificados no primeiro estudo e os indicadores obtidos no segundo foram, pois, tomados como referências iniciais na categorização das informações das entrevistas com os voluntários. As contribuições do instrumento de pesquisa, desenvolvido por Morin Morin, Tonelli, e Pliopas (2003), foram menos expressivas, embora igualmente importantes. 


\section{Discussão dos Resultados}

Os líderes comunitários da Pastoral da Criança que atuam como voluntários em Natal estão distribuídos, uniformemente, em faixas etárias dos 16 aos 47 anos, estando nesse intervalo $89,3 \%$ do total da população. A maioria desses atores sociais é do sexo feminino (78,7\%), sendo $51,7 \%$ são solteiros e $42,1 \%$ casados.

O nível de escolaridade de maior incidência é ensino médio completo (48,3\%). A renda familiar, de um modo geral (84,4\% dos voluntários), está entre 1 e 4 salários mínimos mensais, o que justifica o título da presente investigação. Com relação ao tempo de atuação, 41,2\% dos voluntários atuam de 1 a 12 meses na Pastoral e 26,6\% entre 13 a 24. Entre aqueles que, além de exercer a atividade voluntária estão envolvidos em algum tipo de trabalho remunerado, estão 51,7\% da população.

Conforme registrado anteriormente, as informações aqui discutidas contemplam essa diversidade de perfil.

No intuito de preservar a identidade, os líderes comunitários estão designados, ao longo da apresentação dos resultados, como L1, L2,..., L9. Os resultados concernentes às categorias motivacionais presentes na atividade voluntária desenvolvida, encontram-se estruturados de acordo com as dimensões constantes do modelo de Vroom (1964). A categorização dos resultados, na condição de esforço de aglutinação de elementos similares, não tem caráter estanque. Nesse sentido, é oportuno registrar que, como informações qualitativas, os conteúdos aparecem nas falas dos sujeitos, não raro fazendo referência a valores próximos em sentido semântico.

As categorias identificadas como geradoras de valências, expectativas e instrumentalidades se encontram sintetizadas nos Quadros 5, 6e 7, respectivamente, e são discutidas na sequiência.

De acordo com as informações sintetizadas no Quadro 5, o desenvolvimento interpessoal aparece sob valência positiva elevada, sendo essa a categoria mais expressiva dentre as demais. 
Quadro 5: Indicadores de Valências

\begin{tabular}{l|l|l|l}
\hline \multicolumn{1}{c|}{ Categorias } & \multicolumn{1}{c|}{ Indicadores } & Líderes comunitários & \multicolumn{1}{c}{ Valências } \\
\hline $\begin{array}{l}\text { Desenvolvimento } \\
\text { interpessoal }\end{array}$ & $\begin{array}{l}\text { Crescimento pessoal; auto-estima; } \\
\text { laços de amizade; solidariedade; } \\
\text { qualidade de vida. }\end{array}$ & L1 L9 & $\begin{array}{l}\text { Significativamente } \\
\text { positiva }\end{array}$ \\
\hline $\begin{array}{l}\text { Desenvolvimento } \\
\text { socioprofissional }\end{array}$ & $\begin{array}{l}\text { Novas habilidades; dinamismo e } \\
\text { compromisso social; sentimento de } \\
\text { realizar algo importante. }\end{array}$ & L2, L3, L5, L7, L8, L9 & Positiva \\
\hline Realização & $\begin{array}{l}\text { Satisfação; autonomia; auto-respeito. } \\
\text { Envolvimento }\end{array}$ & $\begin{array}{l}\text { L1, L2, L3, L4, L5, L6, } \\
\text { L7, L9 }\end{array}$ & $\begin{array}{l}\text { Significativamente } \\
\text { positiva }\end{array}$ \\
\hline $\begin{array}{l}\text { Rectividade por parte das crianças e da } \\
\text { comunidade. }\end{array}$ & $\begin{array}{l}\text { Lecomhecimento por p4, L7, L8, L9 } \\
\text { pelo trabalho dos }\end{array}$ & Positiva \\
\hline $\begin{array}{l}\text { Expressão } \\
\text { religiosa }\end{array}$ & $\begin{array}{l}\text { Bem-estar espiritual; realização de } \\
\text { missão religiosa. }\end{array}$ & $\begin{array}{l}\text { L1, L2, L3, L5, L6, L7, } \\
\text { L9 }\end{array}$ & Positiva \\
\hline $\begin{array}{l}\text { Desgaste físico- } \\
\text { emocional }\end{array}$ & $\begin{array}{l}\text { Desgaste físico em virtude das } \\
\text { exigências da tarefa; dificuldade em } \\
\text { conter sentimentos de tristeza; } \\
\text { desespero e revolta diante de situações } \\
\text { vivenciadas. }\end{array}$ & L4, L6 & Negativa \\
\hline
\end{tabular}

Fonte: dados da pesquisa (2003).

Uma das entrevistadas, L2, citou a importância do trabalho voluntário para a auto-estima:

"Eu era do lar, sempre naquela rotina, me sentia uma inútil [...] ainda sou tímida, mas, na Pastoral da Criança, me sinto aprendendo e ensinando [...] quero acreditar mais em mim mesma, na minha capacidade".

Não apenas pelas possibilidades de ensino e de aprendizagem, numa perspectiva individual, mas também pelo desenvolvimento da solidariedade (L2, L3, L4, L6, L8, L9), as valências se manifestam, pois, no conjunto, as vivências promovem a melhoria da qualidade de vida (L1, L3, L6, L8).

Outra categoria com valência significativamente positiva, a realização foi fortemente compartilhada pelos participantes. O depoimento de L3 é ilustrativo:

"É mais gratificante do que a minha profissão [...] é no trabalho da Pastoral que eu me realizo. Na minha profissão eu me sinto impotente para mudar as coisas em que eu não acredito [...] não concordo com o modo como as coisas são conduzidas lá. Na Pastoral da Criança eu tenho essa liberdade, eu posso trabalhar de acordo com o que eu acredito [...] eu encontro a minha compensação" (L3). 
O desgaste físico-emocional apareceu como categoria pouco valorizada. Embora relacionada a aspectos não desejáveis do trabalho, tal manifestação é explicada pelo sentido social subjacente, uma vez que é da natureza da atividade lidar com populações em situações precárias. Esse tipo de ocorrência foi anteriormente constatado por Borges e Alves Filho (2001, p. 184), quando apontaram que, "pela reflexão de Vroom, o dispêndio de energia tende a apresentar valência positiva em ocupações de sentido social mais evidente".

O desgaste físico está associado aos problemas de acesso às comunidades que, conforme registram L4 e L5, é dificultado pela insalubridade e periculosidade locais. Já o desgaste emocional se encontra relacionado a sentimentos vivenciados de tristeza, desespero e revolta, diante de situações para as quais os voluntários não dispõem de recursos suficientes, ou, ainda, diante da dificuldade em manter o controle, ao presenciar cenas dolorosas (L6):

"Uma coisa que eu acho difícil nesse trabalho é que a gente nunca pode demonstrar para as famílias a tristeza, em momentos difíceis que a gente presencia. Por exemplo: cheguei numa casa, estava uma criança pequena almoçando feijão com farinha dentro de uma lata de tinta, e agüentar a dor de ver aquilo e ter que fingir que isso é normal, porque a mãe tinha acabado de vender todas as panelas de casa pra poder comprar aquela comida. [...] E, num momento desses, se a gente deixar descer uma lágrima no rosto, isso vai trazer ainda mais desânimo para aquela mãe".

A valência negativa encontrada, portanto, relaciona-se ao cenário socioeconômico nacional e não ao conteúdo do trabalho em si ou a outras variáveis de comportamento organizacional, tais como relações interpessoais, relações com a chefia, hierarquia e controles do trabalho.

Com relação às expectativas de desenvolvimento interpessoal, foi possível observar que o voluntário as relaciona a aspectos da atividade, como a crença de que, através do trabalho voluntário, pode alcançar uma melhoria da auto-estima (L3, L5, L7, L9) e o crescimento pessoal (L5, L4, L9). 


\section{Quadro 6: Indicadores de Expectativas}

\begin{tabular}{|c|c|c|c|}
\hline Categorias & Indicadores & Líderes comunitários & Expectativas \\
\hline $\begin{array}{l}\text { Desenvolvimento } \\
\text { interpessoal }\end{array}$ & $\begin{array}{l}\text { Crescimento pessoal; auto-estima; } \\
\text { laços de amizade; qualidade de vida. }\end{array}$ & $\begin{array}{l}\text { L3, L4, L5, L6, L7, L8, } \\
\text { L9 }\end{array}$ & Elevada \\
\hline $\begin{array}{l}\text { Desenvolvimento } \\
\text { socioprofissional }\end{array}$ & Novas habilidades & L5, L8, L9 & Elevada \\
\hline Realização & Satisfação; auto-respeito. & L2, L3, L4, L5 & Elevada \\
\hline $\begin{array}{l}\text { Contribuição } \\
\text { social }\end{array}$ & $\begin{array}{l}\text { Promoção de transformações na vida } \\
\text { da comunidade; combate à } \\
\text { desnutrição e a mortalidade infantil; } \\
\text { inclusão social. }\end{array}$ & L1 a L9 & $\begin{array}{l}\text { Significativamente } \\
\text { elevada }\end{array}$ \\
\hline Envolvimento & $\begin{array}{l}\text { Afetividade por parte das crianças e } \\
\text { da comunidade. }\end{array}$ & L2, L3, L4, L7 & Elevada \\
\hline $\begin{array}{l}\text { Expressão } \\
\text { religiosa }\end{array}$ & $\begin{array}{l}\text { Bem-estar espiritual; evangelização } \\
\text { das famílias acompanhadas. }\end{array}$ & L1, L5, L6, L7 & Elevada \\
\hline $\begin{array}{l}\text { Aprimoramento } \\
\text { da gestão de } \\
\text { pessoas }\end{array}$ & $\begin{array}{l}\text { Promoção do espírito de equipe e de } \\
\text { comprometimento por parte dos } \\
\text { voluntários. }\end{array}$ & $\mathrm{L} 2, \mathrm{~L} 3$ & Elevada \\
\hline $\begin{array}{l}\text { Mobilização da } \\
\text { sociedade }\end{array}$ & $\begin{array}{l}\text { Ampliação de parcerias com o } \\
\text { governo e entidades; conscientização } \\
\text { da comunidade, novos voluntários. }\end{array}$ & L2, L4, L6, L8, L9 & Elevada \\
\hline $\begin{array}{l}\text { Reconhecimento } \\
\text { pelo trabalho }\end{array}$ & $\begin{array}{l}\text { Reconhecimento por parte da } \\
\text { comunidade atendida. }\end{array}$ & L4, L5, L6 & Baixa \\
\hline
\end{tabular}

Fonte: dados da pesquisa (2003).

Entretanto as maiores expectativas estão na categoria contribuição social, indicando quanto imaginam poder promover transformações na comunidade:

“A gente busca também maneiras de adquirir renda familiar, cursos, convênios (...) porque as mães começam a perder o gosto de viver dentro daquela vidinha de criar filho (...) a gente quer que elas percebam que elas podem fazer mais, que devem se cuidar (...) que elas não estão isoladas do mundo, trazê-las para a sociedade".

A mobilização da sociedade também foi mencionada para indicar que esperam poder ampliar a rede de parcerias com o governo e outras entidades e conscientizar a comunidade para aumentar a participação voluntária.

O fato de o reconhecimento pelo trabalho ter valência positiva não influencia, portanto, as expectativas dos voluntários, porquanto, mesmo atribuindo ao reconhecimento um fator desejável, os atores não vêem muitas possibilidades de que o esforço realizado garanta o alcance desse resultado. 


\section{Quadro 7: Indicadores das Instrumentalidades do Desempenho}

\begin{tabular}{|c|c|c|c|}
\hline Categorias & Indicadores & Líderes comunitários & Instrumentalidades \\
\hline $\begin{array}{l}\text { Desenvolvimento } \\
\text { interpessoal }\end{array}$ & $\begin{array}{l}\text { Crescimento pessoal; auto-estima; } \\
\text { solidariedade; qualidade de vida. }\end{array}$ & $\begin{array}{l}\text { L1, L2, L3, L4, L6, } \\
\text { L7, L9 }\end{array}$ & Elevada \\
\hline $\begin{array}{l}\text { Desenvolvimento } \\
\text { socioprofissional }\end{array}$ & $\begin{array}{l}\begin{array}{l}\text { Novas habilidades; dinamismo } \\
\text { compromisso social. }\end{array} \\
\text { e }\end{array}$ & L2, L5, L9 & Elevada \\
\hline Contribuição social & $\begin{array}{l}\text { Promoção de transformações na vida } \\
\text { da comunidade; combate à } \\
\text { desnutrição e à mortalidade infantil; } \\
\text { inclusão social. }\end{array}$ & $\begin{array}{l}\text { L1, L2, L3, L4, L5, } \\
\text { L6, L8, L9 }\end{array}$ & Inexpressiva \\
\hline Envolvimento & $\begin{array}{l}\text { Afetividade por parte das crianças e } \\
\text { da comunidade. }\end{array}$ & L2, L3, L4, L7, L8, L9 & Elevada \\
\hline $\begin{array}{l}\text { Reconhecimento } \\
\text { pelo trabalho }\end{array}$ & $\begin{array}{l}\begin{array}{l}\text { Reconhecimento por parte da } \\
\text { comunidade atendida. }\end{array} \\
\end{array}$ & L5 & Elevada \\
\hline Expressão religiosa & $\begin{array}{l}\text { Bem-estar espiritual; evangelização } \\
\text { das famílias acompanhadas. }\end{array}$ & L1, L5, L6, L7 & Inexpressiva \\
\hline $\begin{array}{l}\text { Aprimoramento da } \\
\text { gestão de pessoas }\end{array}$ & $\begin{array}{l}\text { Promoção do espírito de equipe e de } \\
\text { comprometimento entre os } \\
\text { voluntários. }\end{array}$ & L2, L3 & Inexpressiva \\
\hline $\begin{array}{l}\text { Mobilização da } \\
\text { sociedade }\end{array}$ & $\begin{array}{l}\text { Ampliação de parcerias com o } \\
\text { governo e entidades, conscientização } \\
\text { da comunidade, novos voluntários. }\end{array}$ & L2, L4, L6, L8, L9 & Inexpressiva \\
\hline
\end{tabular}

Fonte: dados da pesquisa (2003).

Com relação ao desenvolvimento interpessoal, os participantes percebem que o próprio desempenho é instrumento para tal. O desenvolvimento da solidariedade (L3, L4, L6) apareceu com destaque:

"Antes da PC eu queria ajudar o próximo e não sabia como, eu era mais individualista; depois eu me tornei mais preocupado com o coletivo, me sinto mais gente" (L4).

Há, ainda, a possibilidade de melhorar a auto-estima, porque:

"depois que eu passei a atuar, notei que hoje eu gosto mais de mim. Antes eu não tinha tanto amor a mim como eu tenho agora. Minha auto-estima melhorou" (L7).

De outra forma, a instrumentalidade para a contribuição social, indicada pela maioria, foi menos expressiva, uma vez que, embora em alguns aspectos o desempenho seja apontado como instrumento importante, esse é considerado insuficiente para alcançar resultados. O desempenho na promoção da inclusão social, por exemplo, não encontra resposta satisfatória:

"Percebo que o trabalho com as mães está funcionando, mas ainda falta muito para o objetivo de engajar a mãe na sociedade" (L6).

Esta fala retrata, também, o engajamento social dos atores. 
A oportunidade de promover transformações na comunidade (L1, L2, L3, L9) é outro aspecto em que o desempenho é considerado instrumento importante, porém, insuficiente:

“A gente faz até onde pode, se esforça, mas falta uma política pública, o interesse é muito pouco, nós não temos nem sede própria [...] nós fazemos capacitação, mas muitas vezes não podemos pôr em prática, porque não temos espaço" (L1).

“A teoria acaba sendo diferente da prática, porque não tem estrutura na nossa paróquia [...] mas é possível se fazer mais e a gente faz o mínimo possível, porque as condições não permitem" (L3).

Em virtude dos impedimentos socioeconômicos nas comunidades, há voluntários que recorrem a orações para transformar aquilo que não está ao seu alcance:

"A gente trabalha com multimistura, mas às vezes algumas famílias não têm o alimento para misturar. Alguns pais e mães são viciados e a gente nem pode dar o alimento porque eles vendem. Fica muito difícil, tem que orar e pedir a Deus pra mostrar outro jeito"(L2).

Com relação ao combate à desnutrição e à mortalidade infantil, os voluntários consideram que, embora existam outros problemas nas comunidades, esse objetivo tem sido alcançado (L4, L5, L6, L8).

A análise dos resultados das instrumentalidades conduz à seguinte constatação. Fica evidente que, no cotidiano, os voluntários ampliam os objetivos organizacionais ao perceberem os graves problemas sociais relacionados, por exemplo, à carência de política efetiva voltada ao fornecimento de serviços de saúde e de saneamento públicos. A partir daí, tomam consciência de que os instrumentos de que dispõem não são suficientes para mudar a realidade encontrada.

Esse resultado pode explicar a elevada rotatividade de voluntários, conforme sugerem os dados relativos ao tempo de atuação na Pastoral. Não obstante o fato de existir há mais de 18 anos em Natal, um percentual de 67,8\% dos voluntários está concentrado em tempo de atuação de até 24 meses. Seria, pois, a partir da tomada de consciência da situação socioeconômica da população atendida e da insuficiência dos instrumentos disponíveis para alterar o cenário de miséria encontrado, que o voluntário percebe que a intervenção empreendida não resolve satisfatoriamente as demandas, resultando em baixa instrumentalidade.

Com base nessas inferências e visando à estimativa da força motivacional, foi desenvolvido um esforço subjetivo para superar os cálculos matemáticos propostos no modelo de Vroom sem, contudo, alterar a idéia central, qual seja, aquela relacionada às relações de influência entre as três dimensões: valências, expectativas e instrumentalidades. 
A partir das valências foi possível observar que os resultados do trabalho apontados, em sua maioria, são impregnados de sentimentos positivos, demonstrando que esses são desejáveis pelos voluntários. A única categoria que tendeu para uma valência negativa foi o desgaste físico e emocional, citada por uma parcela menor dos entrevistados, com pouca expressividade.

Os voluntários atribuíram, igualmente, elevadas expectativas a todos os resultados descritos, com exceção ao reconhecimento pelo trabalho. Nesse caso, a exemplo do que ocorreu com a valência, reduzida parte dos participantes relatou não contar com esse resultado, embora o valorize.

Na instrumentalidade, entretanto, ficou nítida a relação entre o desempenho e a recompensa em termos da contribuição social do trabalho. A despeito de ter sido considerado satisfatório em alguns aspectos, especialmente no tocante à superação dos problemas de desnutrição e mortalidade infantil, os voluntários demonstram inquietações em torno do desempenho alcançado, quando constatam a insuficiência dos instrumentos disponíveis na resolução do conjunto das carências da população atendida.

No exame desse quadro, os indicadores conduzem à estimativa de que, conquanto a força motivacional dos voluntários seja considerável, poderia ser mais elevada, não fossem os percalços advindos de circunstâncias sociais adversas, em face das quais se sentem impotentes. A insuficiência do desempenho se encontra atrelada à idéia da incapacidade para enfrentar, com os recursos disponíveis, problemas relativos à infra-estrutura urbana, à ineficiência das políticas públicas ou mesmo ao número insuficiente de voluntários dedicados à causa.

\section{Considerações Finais}

Esta investigação explorou componentes da motivação na atividade voluntária desenvolvida por líderes comunitários da Pastoral da Criança em Natal, utilizando, para este desígnio, o Modelo da Expectância de Vroom (1964).

É oportuno, inicialmente, destacar que, não obstante o fato de o trabalho da Pastoral da Criança ter forte relação com a Igreja, a expressão religiosa, conquanto tenha sido mencionada, não teve expressividade em nenhuma das dimensões de valência, de expectativas e de instrumentalidades. De outra forma, categorias como contribuição social e desenvolvimento interpessoal apareceram com maior significado nas falas dos entrevistados. 
Com relação à força motivacional dos voluntários, é possível inferir que, embora considerável, poderia ser mais significativa, caso a instrumentalidade do desempenho fosse mais elevada, visto que as estimativas mais baixas foram obtidas nesta dimensão e, de outra forma, que as valências e expectativas identificadas foram mais expressivas. Uma vez que a ocorrência se dá em grau inferior ao potencial disponível, é pertinente raciocinar que a motivação latente é elevada, em virtude da predominância de valências e expectativas positivas. Por outro lado, a motivação manifesta é baixa, como consequiência da predominância de instrumentalidade negativa.

Um contraste desse dado com o tempo de atuação, cuja maior incidência é de até 2 anos, permite concluir que, ao ingressarem na Pastoral, os voluntários acalentam elevadas expectativas e sentimentos positivos com relação ao trabalho. Porém, à medida que se vão defrontando com as dificuldades e percebem a insuficiência do trabalho realizado para transformar a realidade social de exclusão a que está submetida a população atendida, reconhecem que estão enfrentando demandas munidos de recursos excessivamente escassos, o que impede o alcance de alguns resultados esperados, influenciando negativamente a motivação.

Reforça tal entendimento o fato de que os resultados do trabalho relacionados ao desenvolvimento interpessoal e socioprofissional foram avaliados positivamente nas três dimensões do modelo, permitindo concluir que a força motivacional se direciona mais fortemente para esse resultado.

Todavia esse fator não é suficiente para manter a motivação, porquanto, uma vez satisfeitos com o desenvolvimento alcançado, os líderes tendem a deixar a atividade. Nesse sentido, estudos complementares com ex-voluntários podem esclarecer os motivos do abandono do trabalho na Pastoral da Criança, permitindo gerar outras reflexões no tema.

Importa registrar o desafio epistemológico enfrentado, uma vez que o estudo desenvolvido envolveu a compreensão do comportamento humano em uma organização voluntária, tendo como referência certa literatura que enfatiza a compreensão do trabalho como sinônimo de emprego e renda. Tal exercício exigiu dos autores a transposição de conceitos para uma realidade diversa em que o trabalho assume outra conotação.

Por fim, é importante salientar que, sendo o Modelo da Expectância uma teoria de processo, os aspectos da motivação dos voluntários da Pastoral da Criança, aqui relatados, são passíveis de alterações ao longo do tempo, em virtude das mudanças que possam vir a ocorrer tanto no contexto da Organização quanto no meio externo. Logo, pressupõe-se que os resultados indicados nessa investigação retratam uma configuração momentânea, que não pode ser interpretada em caráter 
definitivo. Pelo contrário, exige permanente acompanhamento, com vistas a incorporar possíveis (re)arranjos circunstanciais.

Artigo recebido em 01.10.2004. Aprovado em 06.12.2004.

\section{Referencias Bibliográficas}

Alves Filho, A., \&

Araújo, M. A. D. (2001, abril/junho).

Um estudo da força motivacional dos funcionários do Banco do Brasil à luz da teoria de expectativa. Caderno de Pesquisas em Administração, 8(2), 27-40.

Allen, R. E.,

Lucero, M. A,

Van N., \&

Kathleen L. (1997, March).

An examination of the individual's decision to participate in an employee involvement program. Group \& Organization Management, 22(1), 117-143.

Andion, C. (2001).

As particularidades da gestão em organizações da economia solidária. Anais do Encontro Nacional dos Programas de Pós-Graduação em Administração, Campinas, SP, Brasil, 25.

Bardin, L. (1977).

Análise de conteúdo. Lisboa: Setenta.

Borges, L. O., \&

Alves Filho, A. (2001, julho/dezembro). A mensuração da motivação e do significado do trabalho. Estudos de Psicologia, 6(2), 177-194.

Bowditch, J. L., \&

Buono, A. F. (1992).

Elementos de comportamento organizacional. São Paulo: Pioneira.
Coordenação da Pastoral da Criança (2003).

Recuperado em 10 de setembro de 2003 de www.pastoraldacrianca.org.br

Erez,A., \&

Isen, A. M. (2002, December).

The influence of positive affect on the components of the Expetancy Theory. Journal of Applied Psychology, 87(6), 1055-1067.

Fernandes, R. C. (1994).

Privado porém público: o terceiro setor na América Latina. Rio de Janeiro: Relume-Dumará.

Ferris, K. R.,

Dillard, J. F., \&

Nethercott, L. (1980, May).

A comparison of V-I-E model predictions: A cross-national study in professional accounting firms. Accounting Organizations and Society, 5(4), 361-368.

Fischer, T., \&

Melo, V.P. (2003, julho).

Gestão social e as organizações do terceiro setor em Salvador: um enfoque na área de combate à violência. Recuperado em 27 julho, 2003, de http://www.rits.org.br 
Gil,A.C. (1994).

Métodos e técnicas de pesquisa social. São Paulo: Atlas.

Lévy-Leboyer, C. (1994).

A crise das motivações. São Paulo: Atlas.

Manson, J. (1996).

Qualitative researching. Londres: SAGE Publications.

Montaño, C. E. (2002).

Terceiro setor e questão social: crítica ao padrão emergente de intervenção social. São Paulo: Cortez.

Morin, E.,

Tonelli, M. J., \&

Pliopas, A. L. V. (2003).

O trabalho e seus sentidos. Anais do Encontro Nacional dos Programas de Pós-Graduação em Administração, Atibaia, SP, Brasil, 27.

Paula, A. P. P. (1997).

Um estudo de caso da Associação Brasileira de Organizações NãoGovernamentiais: construindo uma nova gestão pública em espaços públicos alternativos. Anais do Encontro Nacional dos Programas de PósGraduação em Administração, Angra dos Reis, RJ, Brasil, 21.

Petras, J. (1998).

A marxist critique of post-marxists. Links, n.9 (1997, November / 1998, February).

Quijano, S. D. de, \&

CID, J. N. (2000).

La autoeficacia y la motivación en el trabajo. Apuntes de Psicología. 18(1), 159-177.
Quijano, S. D. de, \&

CID, J. N. (1998).

Un modelo integrado de la motivación en el trabajo: conceptualización y medida. Revista de Psicología del Trabajo y de las Organizaciones. 14(2), 193-216.

Régis, H. P., \&

Calado, S. M. R. (2001).

A Teoria da Expectância em um modelo de escolha do tipo "WithinSubject": um teste empírico da sua validade para a cultura brasileira. Anais do Encontro Nacional dos Programas de Pós-Graduação em Administração, Campinas, SP, Brasil, 25.

Saks, A. M.,

Wiesner, W. H., \&

Summers R. J. (1994, June).

Effects of job previews on selfselection and job choice. Journal of Vocational Behavior, 44(3), 297-316.

Sanchez, R.,

Truxillo, D. M., \&

Bauer, T. N. (2000, October).

Development and examination of an expectancy based measure of testtaking motivation. Journal of Applied Psychology, 85(5), 739-750.

Serva, M. (1997, novembro/dezembro).

O Estado e as ONG's: uma parceria complexa. Revista de Administração Pública, 31(6), 41-54.

Singer, P. (2000).

Economia solidária: um modo de produção e distribuição. In P. Singer \& A. R. Souza. (Orgs.). A economia solidária no Brasil: a autogestão como resposta ao desemprego. São Paulo: Contexto. 
Souza, W. J. (1999).

Máquinas e sujeitos: experiências de operários têxteis frente à modernização tecnológica. Tese de Doutorado. Universidade Federal do Ceará, Fortaleza, CE, Brasil.
Vainer, C. (2000, janeiro).

Controle político dos miseráveis ou utopia experimental? Revista Unitrabalho Informa, Ano 3 (10), 1-2.

Vroom, V.H. (1964).

Work and motivation. New York: Wiley. 